\title{
A SWOT analysis on the implementation of Building Information Models within the Geospatial Environment
}

\author{
U. Isikdag \\ Independent Consultant, Turkey \\ S. Zlatanova \\ GISt, OTB, TUDelft, The Netherlands
}

\begin{abstract}
Building Information Models as product models and Building Information Modelling as a process which supports information management throughout the lifecycle of a building are becoming more widely used in the Architecture/Engineering/Construction (AEC) industry. In order to facilitate various urban management tasks (such as evacuation operations) and several processes of the construction life cycle(such as site selection) through better automation, information related to buildings needs to be represented in the geospatial environment, i.e. in form of geospatial information. Recent research in the field demonstrated that Building Information Models can be used as the information source when transferring building information into the geospatial environment. In fact although recent efforts have been successful in demonstrating the applicability of this information transfer, most of these efforts were not successful in, bringing up the industrial needs for the implementation, presenting the opportunities that the implementation might bring to the AEC and urban management domains and outlining the technical difficulties of the implementation. The review presented in this paper first focuses on outlining the strengths and weaknesses of using BIMs when acquiring building information and transferring it into the geospatial environment. The review later presents opportunities and threats this implementation might bring to AEC and Urban Management domains.
\end{abstract}

\section{INTRODUCTION}

In the last decade, Building Information Models (BIMs) and model based engineering have become an active research area of construction informatics. The industrial reason behind the rise of trend towards using BIMs and model based engineering can be mentioned as the inadequate interoperability in the industry. In the construction industry, business relationships are temporary and often short-term, bringing together partners who may never work together again. Construction projects are organised on consortia and sub-contract bases, which rapidly bring together partners in relatively short working alliances. This highly fragmented nature of the industry, creates barriers to effective exchange of information (and to integration), between people and between processes. Gallaher et al. (2004) indicated that, US\$15.8B is lost annually in the U.S capital facilities industry due to the lack of interoperability. BIMs today are seen as main facilitators of integration, interoperability, collaboration and process automation in construction industry.

Geospatial information can be defined as the information, which is related to existing topographic and man-made phenomena. In contracts to the BIMs, geospatial features are represented in a particular geographic reference system. Geospatial information and Geographic/Geospatial Information Systems (the systems that manage and process the geospatial information, also known as GIS) are used in various fields related to urban built environment and construction 
industry, ranging from three dimensional cityscape visualisations to management of vehicles in the construction site.

In order to effectively automate, some urban management tasks and several processes in the construction life cycle, information related to buildings, needs to be represented in the geospatial environment, i.e. in form of geospatial information. Several tasks of urban management such as emergency response management and indoor navigation and some processes in the construction life cycle, like site selection (i.e. selection of the land plot for a designed project) can be facilitated through the use of certain and sometimes high amount of, geometrical and semantic information about a buildings within the geospatial environment.

Isikdag (2006) stated that although the BIMs contain geometrical and semantic information about the building elements in an object oriented data structure, the information in BIMs can not be easily transferred into the geospatial environment, due to technological barriers. These barriers have risen as building information and geospatial information models (are developed for different purposes, by researchers coming from different backgrounds, in result they) represent, handle and threat the data in different ways. These barriers in turn, prevented a better or full automation of several processes in the construction life cycle and in urban management. Until recent years, the transfer of ' $3 \mathrm{D}$ geometrical and associated semantic information' from building models to the geospatial environment could not be accomplished. This was mainly because of, the lack of ability to store semantic information and the lack of object oriented data structures, in standard CAD models. In contrast, today BIMs (i.e. IFC, as a maturing standard), are capable of containing geometrical and semantic information about the building elements, in an object oriented data structure.

In last three years, there have been various successful academic and industrial efforts to simplify BIMs and implement them within the geospatial context. These efforts will be elaborated in the following section. Although these efforts have been successful in demonstrating the technical aspect of the applicability of the implementation, most of these were not very successful neither in underlining the needs for the implementation, nor in presenting the opportunities that the implementation might bring to the AEC and urban management domains. The review that will be presented in this paper, will focus on a SWOT (Strengths/Weaknesses/Opportunities/ Threats) analysis, in order to identify the needs for such an implementation, outline the opportunities it might bring, and point out the weaknesses and threats that might limit the applicability of such an implementation.

\section{BACKGROUND}

\subsection{Building Information Modelling}

A Building Information Model (BIM) can be defined as, 'a digital representation of physical and functional characteristics of a single building. As such, it serves as a shared knowledge resource for information about a building forming a reliable basis for decisions, during its lifecycle from inception onwards' (NBIMS, 2006). As explained in NBIMS (2006), a basic premise of a Building Information Modeling process is the collaboration by different stakeholders at different phases of the life cycle of a single building in order to (insert, extract, update or) modify information in the digital model in order to support and reflect the roles of that stakeholder. A BIM is a shared digital representation of a single building, founded on open standards for interoperability. The representation may also the cover the objects in the building site, in modelling practice a single building is associated with a single site and vice versa. In last ten years, a BIM (namely Industry Foundation Classes,-IFC-), which is defined by an international industrial alliance is maturing as a standard model, in supporting the various phases of the construction life cycle.

Research in the filed is still working on defining the concepts of Building Information Model and Building Information Modelling. In an effort to define the latter term Howell and Batcheler (2005) summarised the industrial interpretation of Building Information Modelling by providing the different approaches taken by different software vendors in the area. Two of the approaches which were summarised in the paper include, 
- Transitional approach where a building model is created as a loosely-coupled collection of drawings, each representing a portion of the complete BIM. These drawings are then aggregated through various mechanisms to generate additional views of the building, reports and schedules as though there was a single BIM at the centre,

- Central project database approach where the building model is stored in a central project database and managed using a software or an integrated system. The strength of this approach is the ability to organise every building element in one database, thus providing users the chance to immediately see the results of any design revisions made in the model, have them reflected in the associated views, as well as to detect any coordination issues.

In light of these definitions, the approaches to Building Information Modelling can be classified as model centric and system centric. A model centric approach views BIM as a central project repository and provides ways and methods to manage it. In contrast a system centric approach views BIM as a set of drawings and information models in a federated data layer and provides tools to manage several models in this data layer. In parallel, based on the work of Isikdag et al (2007) the definitive characteristics of Building Information Models can be given as being;

1. Object Oriented: most of the BIMs are defined in an object-oriented nature.

2. Data-rich / Comprehensive: BIMs are data rich and comprehensive as they cover all physical and functional characteristics of the building.

3. Three dimensional: BIMs always represent the geometry of the building in three dimensions.

4. Spatially-related: Spatial relationships between building elements are maintained in the BIMs in a hierarchical manner (allowing for several representations such as Constructive Solid Geometry, Sweeping and Boundary representations),

5. Rich in semantics: BIMs maintain a high amount of semantic (functional) information about the building elements.

and finally,

6. BIMs support view generation: The model views are subsets or snapshots of the model that can be generated from the base information model. The model views can be automatically derived with respect to the user needs.

Today, an implementation of BIM paradigm is achieved by using Industry Foundation Classes (IFC) models. Currently, several CAD/AEC (e.g. Bentley, AutoCAD, Archicad) and structural analysis applications (such as SAP 2000) are capable of importing and exporting their internal models as IFCs, and some applications (e.g. Archicad) are also capable of acquiring information from an IFC model through the use of a shared resource such as a shared file or a model server database

\subsection{Representing 3D Building Information within the Geospatial Environment}

Three dimensional representation of urban environment has been an active research topic for last ten years. Research in the area indicates that (geometric) information about buildings and its integration with GI environment are the two key elements when representing the urban environment in 3D.

Three approaches can be used to acquire (geometric) information about buildings and transfer it into the geospatial environment.

First approach is, -measuring and 3D reconstruction- where information about an existing building is collected from (a) single or multiple source(s) and geospatial models are created with respect to an application. Measuring and 3D reconstruction has a long history. A variety of approaches can be used for this (Tao, 2006). 3D Laser Scanning Technology has emerged as the most innovative method and much research is devoted to developing automatic algorithms for 3D reconstruction (i.e. Arayici, 2007, Kang et al 2007, Pu 2007). In fact, such approaches are gathering geometric information about building façades and are not commonly used to acquire information from indoor spaces. However, many public buildings (mostly tourist attractions) have been scanned from inside, but most of them modelled manually (i.e. Meijers et al 
2005). Two drawbacks of 3D reconstruction are i) modelling indoor spaces is a time consuming process that involves much manual effort, and ii) as the main purpose is acquiring the geometry of the building elements, the final model contains limited semantic information.

The second approach in integration of buildings in the topographic (GI) environment is accomplished through acquiring building information from 2D and 3D CAD drawings. Current research for representing building information within the geospatial environment, stemmed from the research related to the integration of CAD and Geographical/Geospatial Information (GI) systems. Thus, the problems related to this approach are generally referred as the CADGIS integration problem. Barriers preventing information exchange have risen between CAD and GI systems due to lack of integration between software systems, as these systems are coming from different backgrounds, developed with different philosophies, and their interpretation of the world is completely different from each other. In result, one of these systems can not understand and interpret the other's data with all aspects of it. CAD systems are developed to model objects that do not exist, and designed for representing the maximum level of detail in terms of, geometry and attributes of the model. On the other hand, GIS are developed to represent objects that already exist around us, and geospatial data models are defined for representing the objects in the most abstract way (specifically in terms of geometry).The efforts for integrating the models of CAD and GI systems were assisted in, creating more effective facilities management systems, enabling photo-realistic 3D visualisations of the city, efficiently managing infrastructure systems, the enterprise-wide use of GISs. These efforts were mainly focused on facilitating data migration from CAD into the geospatial environment. Noonan and Cisson (2001) outlined the technical problems faced during data migration from CAD to GIS as, rare attribution and lack of topology in CAD files, coordinate system differences, layers used differently in CAD and GI systems (i.e. some objects contained in one CAD layer, will be contained in several different GIS layers.) and incomplete geometries that exist in CAD files. Many researchers have investigated the differences and the similarities between CAD and GIS and suggested approaches for transforming information from one to other. As mentioned by van Oosterom et al (2006);

- Lack of object definitions in the CAD files,

- Different scale representations,

- Transformation of the local (CAD) coordinates into a geospatial coordinate system,

- Existence of parametric shapes in CAD files that can not be converted into GIS objects

- Different levels of detail between CAD models and their representation in the geospatial environment appeared as main barriers that prevent CAD-GIS data transformation.

Several studies in the field such as Van Oosterom et al (2006) and Zlatanova et al (2006) have indicated, the need of integrated geometric models and harmonised semantics between two domains and the need for development of uniform data types for both CAD and geospatial information models to tackle the information sharing and exchange problems between AEC and geospatial information domains.

Similar to the previous approach, acquiring the geometry and semantics can also be cumbersome in this approach, but a certain level of semantic information can be transformed from CAD drawings (manually) as most blueprints contain a high level of semantic information about building components. Both these approaches may result in outdated 3D building models in the geospatial environment. This might either be due to, the data acquisition/3D reconstruction process which might be very time consuming or the blueprints which can be modified during the construction stage.

Recent developments in the field of construction informatics have resulted with the emergence of Building Information Models (BIMs).In contrast to the standard CAD models, BIMs of today are capable of containing both 3D geometric/semantic information as they are developed with the intention of covering all stage of the building/facility lifecycle (i.e from the concept design to maintenance /demolition).

The third approach for acquiring 3D building information is, using digital BIMs, and simplifying them (geometrically and semantically). As mentioned previously, BIM are objectoriented, semantically-rich, up-to-date and allow query of needed building parts in views. 
In last three years, there have been various successful academic and industrial efforts to simplify BIMs and implement them within the geospatial context. For example in a recent effort, Isikdag (2006) demonstrated the transfer of information from an industry standard BIM (IFC) to the (ESRI) Shapefiles and Geodatabases. In parallel, commercial software for conversion from IFC to CityGML and vice versa is in development (i.e. IfcExplorer, 2008; Safe Software, 2008). OGC Web Services Phase 4 (OWS-4) testbed initiative looked at how CAD/GIS/BIM information can be integrated at web services level (OWS-4 Summary Document, 2007) and in this context OGC has completed tests on the integration of CityGML and IFC models in OWS-4 testbed (Lapierre and Cote, 2008).In fact, algorithms for seamless conversion from BIMs into the geospatial environment are still in development.

\section{THE SWOT ANALYSIS}

\subsection{How, Why and So What?}

SWOT is an acronym for Strengths, Weaknesses, Opportunities and Threats, and perhaps the most well known approach for defining strategy (Zach,1999). It is used to analyse these four factors that either apply to a business or to an organisation. The technique is mainly used for a analysing a company's internal capabilities (i.e. strengths and weaknesses) in relation to the competitive environment (i.e. opportunities and threats) (Avison and Fitzgerald, 2006) .In this review, the SWOT analysis is used within a different perspective.

The first stage of the analysis focuses on the technical perspective of the implementation and evaluates the advantages and disadvantages that appear as a result of using BIMs in acquiring building information and transferring it into the geospatial environment. The research question that is focused in this stage is;

\section{How can we implement the BIMs in geospatial environment?}

In response, this study evaluates the (technical) advantages and disadvantages as the strengths and weaknesses in the implementation that appear as a result of 'using BIMs for acquiring building information'. Other technical strengths and weaknesses that might appear by the use of different geospatial models (in representing the building in the geospatial environment) is out of the context of this review. The second stage of the analysis is concentrated on the following questions;

Why do we need to implement BIMs in geospatial environment?

What will be the consequences of the implementation?

In response, the second stage of the analysis on the opportunities and threats reveals some facts which might help in answering these questions (by outlining the reasons behind the implementation of BIMs within the geospatial context from the AEC and urban management knowledge domain perspectives). For example, the implementation can facilitate, tasks related to site selection, evacuation activities in an emergency situation and delivery of goods and services which might be classified as the opportunities provided by the implementation. On the other hand some negative consequences of the implementation might appear, such as limitations on personal privacy and threats related to terrorism.

The following sections first explore the strengths and weaknesses of the implementation from the technical point of view, and later investigate the opportunities and threats that emerge as a result of this implementation. 


\section{STRENGTHS AND WEAKNESSES}

In this section, the strengths and weaknesses appear by the implementation of BIMs in geospatial environment are classified in two themes. The first theme investigates the strengths and the second theme illustrates the weaknesses that emerge as result of using BIMs for acquiring building information, to transfer into the geospatial environment.

Theme 1: Strengths of using Building Information Models in acquiring Building Information

\subsection{Strength $\rightarrow 3 D$ Representation of Building Geometry}

As explained in the Section 2.2 digital building models have been in form of -CAD Modelsfor many years. Most of these CAD models are in form of 2D construction blueprints / whiteprints. These documents usually provide elevation, cross-section drawing and drawings that demonstrate the details of structural elements. In contrast the BIMs of today provide 3D representation of all building elements, including the Heating/Ventilation/Air-Conditioning (HVAC) components. The 3D geometrical representation is one of the biggest differences between the BIMs of today and standard CAD models. 3D geometrical representation is the biggest reason behind using BIMs as -source models- for acquiring the 3D geometry of buildings.

\subsection{Strength $\rightarrow$ Spatial Hierarchy represented within an Object Oriented Data Model}

In BIMs the spatial hierarchy between building elements is represented within an object oriented data model. For example, in IFC, a project (the highest level entity) is related with multiple sites, a site may contain multiple buildings and a building is composed of multiple stories. Figure 1 presents an overview of representation of high-level elements within the spatial structure of the model

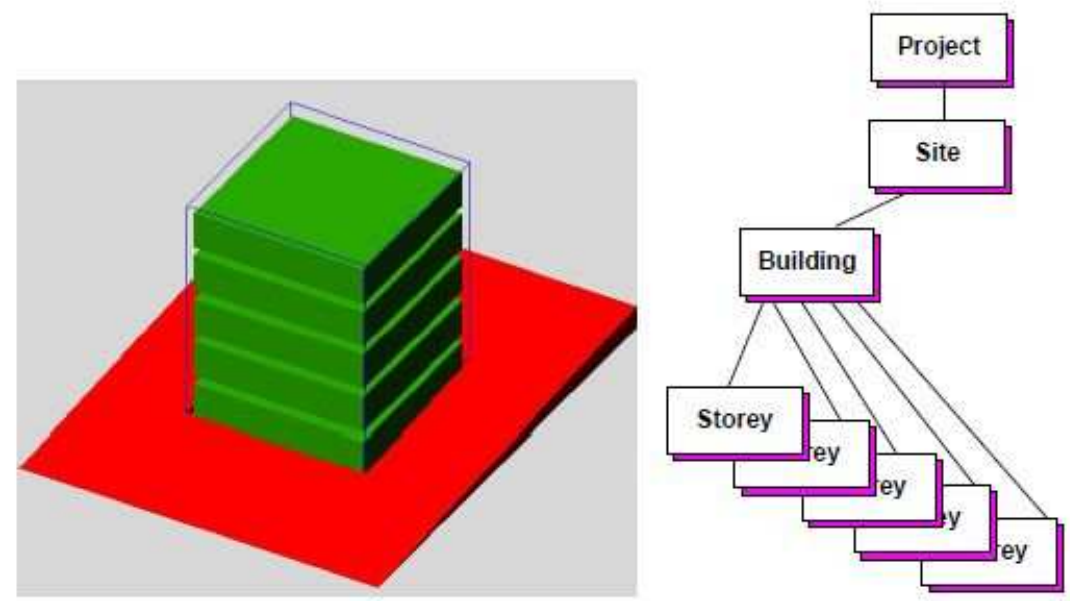

Figure 1. Representation of spatial hierarchy in high-level elements of IFC

This spatial and semantic hierarchy is represented within the object model of IFC. The relation between the classes that represent high-level elements (IfcSite, IfcBuilding, IfcBuildingStorey) is established by using another class (IfcRelAggregates). The graph depicting the object hierarchy between these high level elements is presented in Figure 2. Similar to the hierarchy mentioned above, a building storey can contain a number of walls, columns, beams and slabs. Then a slab can contain an opening element, or a wall can contain number of opening elements, which then can contain doors and windows. All these relationships are stored within the object model of the IFC. The Hello Wall example of BuildingSmart (HelloWall,2008) provides ex- 
tensive information on the spatial hierarchy between a Wall element, its containers and the items it contains.

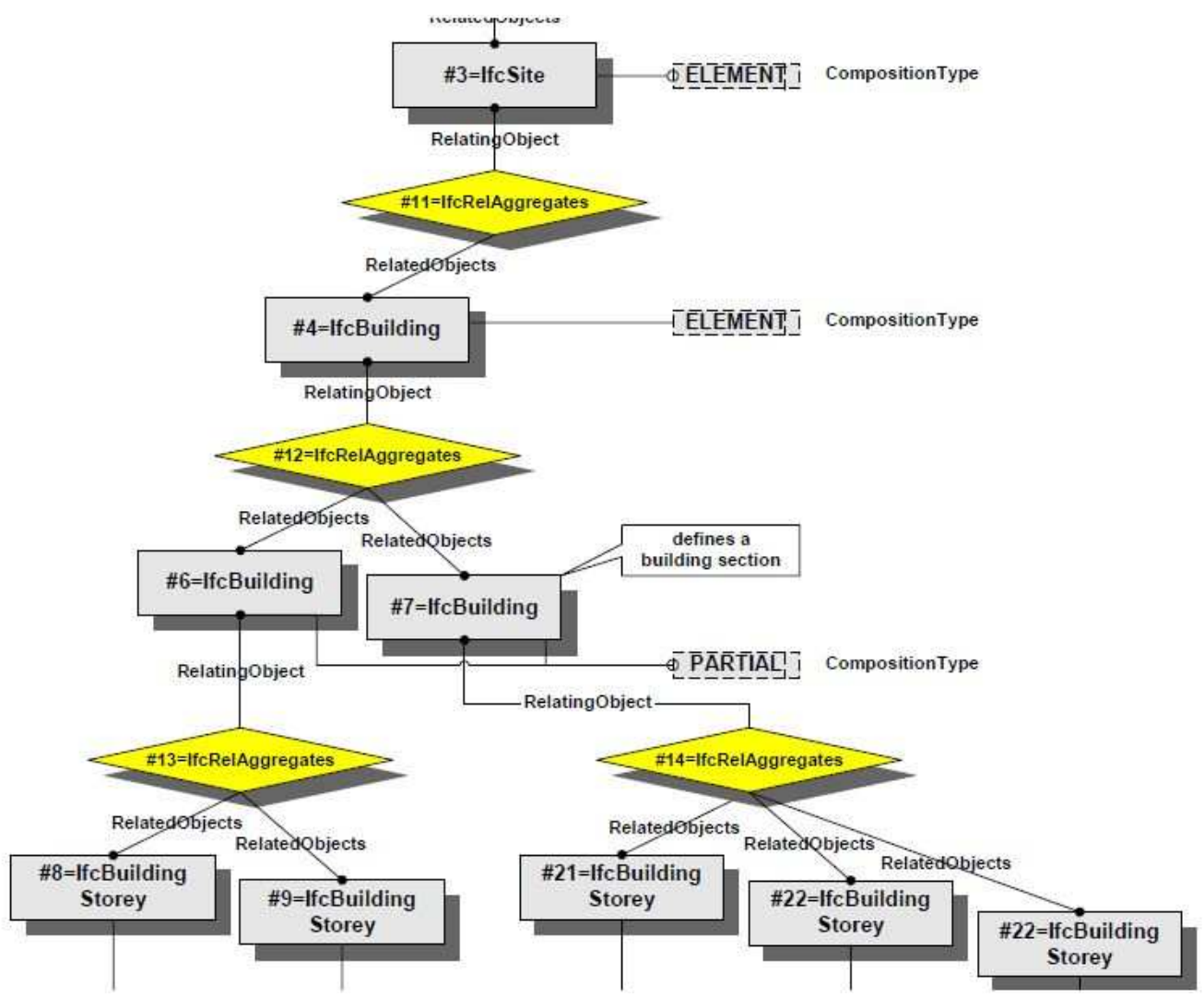

Figure 2. The object model showing the spatial hierarch between IfcSite, IfcBuilding and IfcBuilding Storey classes

The transfer of the representation of the spatial structure (within the object oriented model) provides the opportunity to find answers to the semantic queries such as;

- Which storey has rooms with no windows?

- Which room has a slab with an opening?

- Which rooms contain more than one door?

- How many stories contain rooms which have more than one door?

In fact, it should be noted that it is not easy to define these relationships when an old building have to be re-modelled as an IFC model, as the subdivision of space is not very clear. The same problem is also evident when modelling multi purpose buildings.

\subsection{Strength $\rightarrow$ BIMs contain Rich Semantic Information}

The semantic information in the BIMs is not limited with the information on the building elements (which is stored in the object model of the BIM). Additional information regarding material(s) of the elements and schedule of construction can be obtained from the models.

The information related to material of walls and exists (doors and windows) can play a vital role in an emergency evacuation procedure. The schedule information will aid in the development of large-scale 4D simulations. 


\subsubsection{Strength $\rightarrow$ Evolving Model that represents the Current State of the Building}

The BIMs are developed with the aim of representing the every state of the construction (and building). During the construction stage different views of the model can demonstrate the constructed and -not yet constructed- parts of the building. The living model concept behind the BIMs, makes it foreseeable that the model will reflect current condition of the building after construction stage is over, and this will facilitate some facilities management tasks.

For example, it will be possible to easily locate and navigate to a broken HVAC element, by using BIM, 3D navigation algorithms, and 3D geo-coding. In such a situation, as the BIM will be aware of which HVAC element is broken down, as the indecent occurs the FM staff will get notified, and (even if they have never visited the building before) the will be able to find that element easily with the help of 3D navigation algorithms and 3D geo-coding.

On the other hand, in a fire response operation, views from the evolving BIM can help in providing the current geometrical form of the building to the emergency response personnel (e.g. stairs to reach level $\mathrm{N}$ of the building still might not been built at the time fire occurs in a that level, thus having an access to such information will enable the fire brigade staff to select suitable vehicles in advance, before leaving the fire brigade station)

\subsection{Strength $\rightarrow$ Query based representation of indoor geometry}

The transfer of BIMs into the geospatial environment enables representation of indoor geometry within the geospatial environment (and 3D city models) as a result of a semantic query (i.e. Figure 3 presents the visual representation of an indoor space within a BIM that is transferred into the geospatial environment).

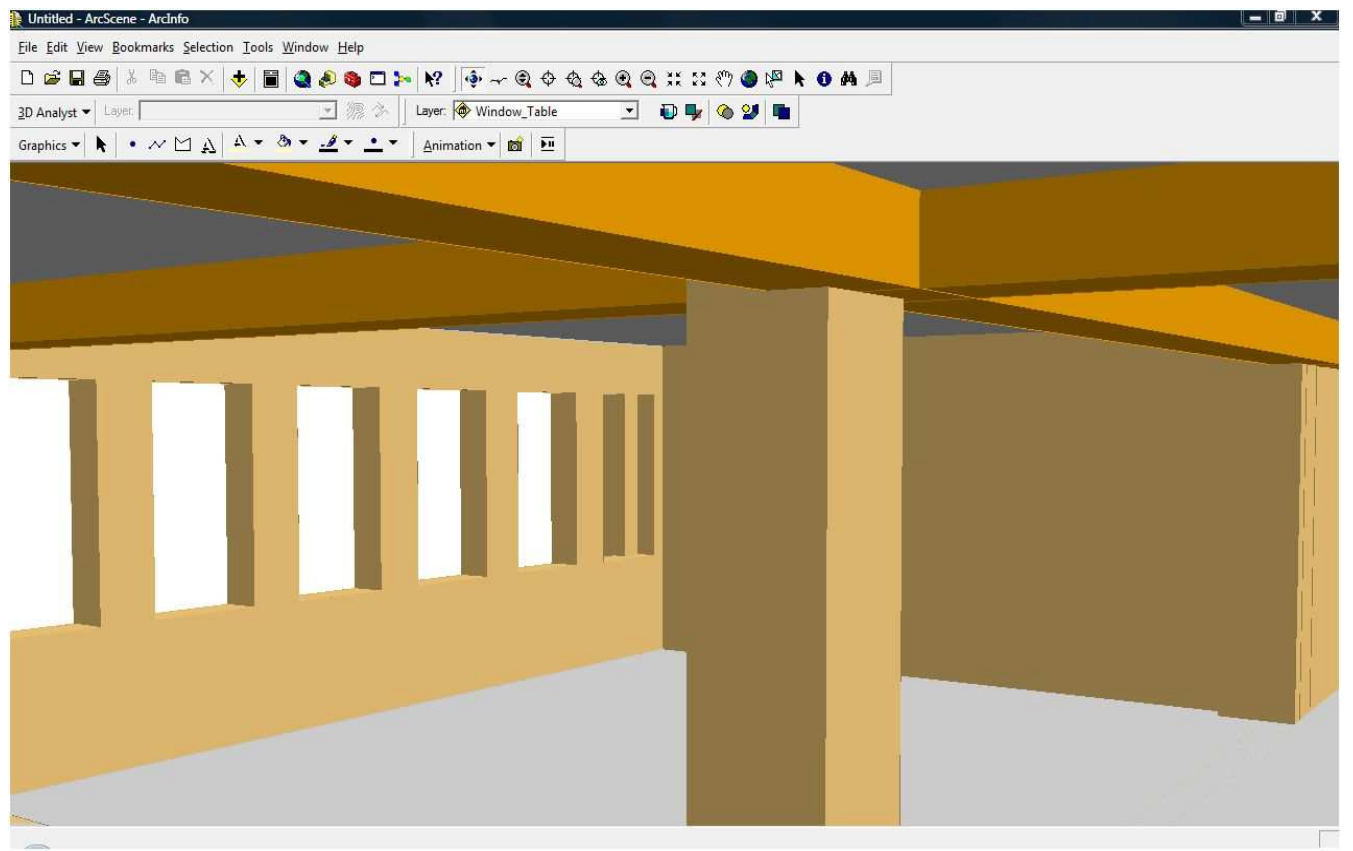

Figure 3. Indoor representation of a BIM within a GIS

Thus, it will be possible to transfer and represent the geometry of building elements with regard to the needs of a specific application. This will prevent the transfer and representation of the geometry of unnecessary elements. This will facilitate the usability of applications requiring data-on-demand and real time information transfer. 


\subsection{Strength $\rightarrow$ Clear space subdivision}

The only international approved standard BIM is ISO PAS 16739 (also known as IFC). The IFC model represents the space inside the room with IfcSpace class, and the geometry of the spaces is stored within the model. The information in room spaces can be useful in analysis related to energy consumption.

Theme 2: Weaknesses caused by the use of BIMs in acquiring Building Information

\subsection{Weakness $\rightarrow$ Differences in geometric representation of objects in AEC and Geospatial Information Domains}

Geospatial Information Models are developed for various purposes and geometric representation (and associated semantics) of real-world objects differ in them depending on the aspect (focus) of the model and the level-of-detail that the model is aiming to represent. For instance, while a Building Information Model represents a building geometry in 3D , a Geospatial Information Model developed for representing a railway network will represent the real-world entity by a node. Similarly, a CityGML LOD 1 model will represent the building geometry by Zextrusion of its 2D floor surface. This type of geometric inconsistencies between representations also needs to be taken into account when integrating the geometric models of in-building HVAC systems and city-wide utility networks.

\subsection{Weakness $\rightarrow$ BIMs use local and relative coordinates}

BIMs use Cartesian coordinate system in Euclidian space $\left(\mathrm{R}^{3}\right)$.This is different from geographic, geodetic and projected coordinate systems used within the geospatial environment. Transformation of coordinates from Cartesian systems to World Geographical System or one of the projected coordinate systems (i.e. UTM) always becomes a need during the data transformation. The second difficulty in the process occurs as each building element is positioned within its own local coordinate system in the BIMs. Although all elements use Cartesian coordinates, they can be relative, e.g. the X-axis of an element (i.e. window) can correspond to Y-axis of its container (i.e. opening). Thus a series of calculations need to be completed to find out the abso-

lute coordinates of every building element in $\mathrm{R}^{3}$, before transforming these coordinates into a geodetic(or projected) coordinate system.

\subsection{Weakness $\rightarrow$ Spatial relationships are not stored in form of connectivity relationships}

In BIMs the geometry of the building elements is represented by the geometrical model, i.e. in form of isolated objects. In fact, as the geometry is considered as an attribute of a building element the spatial relation between the building are established with the semantic relation between different building elements. For example, in IFC model a building contains several building stories, and this relationship is established through the object relationship between

\section{IfcBuilding $\rightarrow$ IfcRelAggregates $\rightarrow$ IfcBuildingStorey}

classes (Figure 2). Although IfcBuilding and IfcBuildingStorey classes are connected semantically (and the connectivity between the elements' geometry can be deduced from that semantic connection), it is impossible to topologically prove the geometry of the building storey is contained within the building's geometry. Only BRep connectivity is maintained locally (within the geometric representation of a class, when the geometric representation is given as BRep). In summary, BIMs currently do not support 3D topology and can be regarded as geometric models with semantically described relationships. Ongoing research in the area, i.e. Paul and Borrmann (2008) is able to provide approaches for establishing topological relationships in BIMs. 


\subsection{Weakness $\rightarrow$ Multiple geometrical representations}

In BIMs (and specifically in IFC) the geometry of the building elements is represented with multiple geometric representation types. The geometry can either be represented separately by these representations (i.e. BRep and Sweeping) for different implementation aspects or (most commonly) the geometry of the element is represented by a combination of different geometric representations (i.e Sweeping and CSG). Although presenting the element geometries within multiple representations can be regarded as strength of the BIM, this in turn brings on the need for mapping between CSG/Sweeping representations to BRep (which is the commonly used geometrical representations in the geospatial environment.).This limitation might negatively impact the development curve of the (information) mapping software.

\subsection{Weakness $\rightarrow$ Class differences}

BIM classes correspond to the building parts with respect to the construction design. This might not necessarily correspond to the GI perception for that building part. For example, the floor of a particular room is not readily available in a BIM class.

\section{OPPORTUNITIES AND THREATS}

In this section, the opportunities and threats appear by the implementation of BIMs in geospatial environment are classified into themes. First two themes present the opportunities to facilitate the tasks in the AEC domain and the opportunities to facilitate the tasks in urban management domain. The opportunities to facilitate the tasks in the AEC domain (Theme 1) are presented in parallel with the building lifecycle stages (of Omniclass, 2006). The $3^{\text {rd }}$ theme summarises the threats that might appear as a result of the implementation.

Theme 1: Opportunities for the AEC domain

\subsection{Opportunity $\rightarrow$ Facilitating Site Selection (Omniclass Stage: N/A)}

The implementation of BIMs in geospatial environment will facilitate the site selection process, by enabling better automation of several tasks in the process. The site selection is mostly completed, at the initiation of a construction project. In most countries, a GIS is used in support of this analysis, several tasks needs to be completed on paper due to the barriers preventing the automatic transfer of semantic information into the geospatial environment. As explained in Isikdag (2006) the site selection analysis can be in three forms:

- Looking for a site without having a designed project (Omniclass Stage: Conception)

- Having a site and making a what-if analysis to select a project from multiple proposed projects.

- Looking for a site while having a designed project.

The first form never benefit from an implementation of BIM in geospatial context due to its nature, i.e. in the process there will not be a need for project (or building) information. On the other hand, if the process will be in the second or third form, transferring information from the BIM into the geospatial environment, will support the process. For example, as explained in Isikdag (2006) when the geometric representation of the floor plan, floor plan area and number of stories is transferred into the geospatial environment, this information will be sufficient to complete the analysis (of latter two forms) by using a GIS in Turkey. The role of well-formed digital city models is also very important in facilitating this process, as these models can act as an information infrastructure for the overall process. 


\subsection{Opportunity $\rightarrow$ Evaluation of Design Proposals (Omniclass Stage: Design)}

A key study about three dimensional representation of urban fabric, Cote (2002), pointed out that, in most cities the information infrastructure does not yet adequately represent the fullness of important three-dimensional aspects of the city, to answer the questions such as "What windows have views of a particular spot?", "How will a design proposal affect views and shadows in an urban scene?". The implementation of BIMs in the geospatial environment will help in evaluation of the design proposals both from public and client perspectives, and finding answer to these questions.

\subsection{Opportunity $\rightarrow$ Facilitating the analysis on energy consumption and lightning requirements (Omniclass Stage: Design)}

Several EU projects such as DIVERCITY (Divercity Handbook, 2003) have demonstrated how acoustics, thermal and lightning simulations can be accomplished by using BIMs. The analysis on energy consumption will benefit from thermal simulations within GIS. On the other hand, conditions that affect both the lighting and thermal requirements is related to the geographic location of the room. Different elements of natural and built environment (i.e. hills, trees, buildings) can affect these requirements (these elements can create shadows, might cause difficulties in air ventilation), thus developing integrated models that take these factors into account (i.e. geo-virtual environments as mentioned in Kibria,2008) will facilitate the analysis on energy consumption and lighting requirements.

\subsection{Opportunity $\rightarrow$ Integration of logistics operations into large-scale $4 D$ simulations} (Omniclass Stage: Execution)

In AEC industry, 4D models known as models that combine 3D models and time information on construction activities to demonstrate the progress of construction over time. 4D simulations are useful in understanding the clashes in the process and they improve communication in the project management tasks. The 4D simulations are usually done within in-house developed software systems, but in recent years some commercial off-the-shelf systems are also emerging (Vico,2008, Synchro,2008). Construction enterprises might have different projects running in different parts of a city (or different cities), in this situation the enterprise need to carry out logistics operations between its construction sites. Logistics operations are usually managed within a geospatial environment, and if required level and amount of geometric and semantic information can be transferred into the geospatial environment, these 4D simulations can be completed within a geospatial (geo-virtual) environment and can be extended to cover the logistic operations.

\subsection{Opportunity $\rightarrow$ Assessment of damage (and in support renovation projects) (Omniclass Stage: Design/Utilization)}

There have been many studies that looked at the impact of flood to urban areas using GIS, some examples are Apirumanekul and Mark(2001), Campana and Tucci (2001), Mark et al. (2004), and Brown and Johnson (2005). On the other hand, several studies (i.e. Gunes and Kovel (2000) investigated how post-disaster emergency response operations (in flooding) can be managed using a GIS. The transfer of semantic information from BIMs into the geospatial environment will help in assessing the damage caused by the flood. For example questions such as, "Which elements of electrical wiring might be damaged?", "Which parts of the HVAC systems can be broken down?", "Which wall's covering needs to replaced after the flood?" can be answered by using the building information acquired from the model, i.e. without visiting the actual site. On the other hand, the assessment of the damage after a disaster will support the design stage of a renovation project ( i.e. when the new owner of a building the might ask to remove some building elements(i.e. walls, doors, windows) after assessing their post-disaster condition ) 
Theme 2: Opportunities for Urban Management domain

\subsection{Opportunity $\rightarrow$ Facilitating 3D Modelling of Urban Environment}

Recent developments in the area of urban modelling have demonstrated that, it is possible to represent the urban environment by 3D digital city models. As explained in Kibria (2008) these models can facilitate for shade shadow, sun path, visibility and wind flow analysis. The most commonly known standard in the area is CityGML. CityGML Implementation Specification (2007) defines CityGML as a common semantic information model for the representation of 3D urban objects that can be shared over different applications. In CityGML, 5 levels of detail (LOD) were defined in order to represent city objects. In terms of representing buildings, 4 out of five LODs are used. As explained by CityGML Implementation Specification (2007), LOD1 is the well-known blocks model comprising prismatic buildings with flat roofs, a building in LOD2 has differentiated roof structures and thematically differentiated surfaces. On the other hand, LOD3 denotes architectural models with detailed wall and roof structures, balconies, bays and projections. High-resolution textures can be mapped onto these structures. In LOD 4 of the model, interior structure of the building can be represented (but in a more simplified manner than a BIM).Recent research have demonstrated some successful examples on the information mapping from BIM (IFC) models into the CityGML models (IfcExplorer, 2008; Safe Software, 2008, Lapierre and Cote, 2008), but there still is a need for a formal framework for this mapping process. The technical needs for a formal framework for strict (semantic and geometry) conversion is elaborated in Isikdag and Zlatanova (2008).

\subsection{Opportunity $\rightarrow$ Facilitating Evacuation Activities}

The implementation will facilitate the emergency response operations in a fire or flood situation. Emergency responders (e.g. fire fighters) are generally not aware of the interior structure, furniture, used materials, etc. of a building. In many European countries, the only information available within the fire brigade is a plan map indicating the exits on the ground floor. Floor plans (if not damaged by the fire/flood) might be obtained from the various spots/ or facility management office in that particular building, but they may be outdated and do not provide details on semantic information. The implementation of BIMs within the geospatial context will provide emergency responders with tools that will help in two aspects, i) these tools will facilitate orienting (as, the response personnel will know the geometry of the construction and possible exits in advance) and ii) these tools will also will enable safer indoor navigation and evacuation (as they will be informed about the usage type of the different rooms, e.g.- a room might contain flammable chemicals, and materials of the building elements -e.g. a type of flooring might get slippery when its wet). Isikdag et al (2008) provides a recent case study on assessing the role of BIMs in a fire response management process. In addition as Cote (2002) indicated such an implementation can help in answering the question of "How many square feet of commercial/office/housing might be affected by an emergency in a given area?".

\subsection{Opportunity $\rightarrow 3$ D Geo-coding}

Geo-coding is known as the process of assigning geographic identifiers (i.e. coordinates) to any type information. The geo-coding process involves transforming descriptive location information into an absolute geographic reference. Today the most common data that is geo-coded still is the postal addresses. Efforts towards developing 3D (indoor) geo-coding systems have started to emerge in recent years (i.e. Beal, 2003; Lee, 2004; Lee and Kim, 2006). The implementation of BIMs in geospatial context will help in developing models and algorithms for 3D geo-coding In parallel, 3D geo-coding and address-matching together with developments in indoor navigation will facilitate all location based services including the delivery of goods and services (indoors). 


\subsection{Opportunity $\rightarrow$ Registration of Ownership Rights in 3D Cadastre}

In some countries there have been efforts on storing the cadastral information (registrations) with 3D geospatial information models. The transfer of information from BIMs into the geospatial environment can aid in registration of apartment rights and rights related to different spaces in other elements of the built environment (i.e. shops, shopping arcades, garages ) in 3D cadastral registries. Further information on the issue can be found in Stoter (2004).

\subsection{Opportunity $\rightarrow$ Public Participation}

The presentation of building information (with high detailed geometry and rich semantic information) within the geospatial environment will help the decision making process through facilitating public participation in urban and regional level planning activities (such as evaluation of design proposals). The need of shared collaborative environments in the field is becoming clearer every day and in the near future and BIMs will be the main information source for collaborative online public participation platforms for accessing building information.

\subsection{Opportunity $\rightarrow$ Property Tax Evaluation}

In some countries, such as US, the property tax evaluation process requires geometric and semantic information on building elements/parts and furniture, such as the precise dimensions of the rooms, and the number and type of fixtures located within the house. In addition, any structural changes in the house or property will change the amount of the tax. The implementation of Building Information Models in geospatial environment can facilitate the tax evaluation process at urban level by providing up-to-date information on current state of buildings(in terms of geometry of building and other installations and movable objects) when required by the taxing authority.

Theme 3: Threats

\subsection{Threat $\rightarrow$ Limitations on personal privacy and anonymity}

The implementation of BIMs in the geospatial context, and the developments in the field of 3D geo-coding will facilitate indoor navigation and this in parallel will ease the tracking of objects and people within the buildings. In the future, more prevalent use of RFID tags will contribute to the track-ability of people and objects, for example a student carrying an RFID equipped ID Card can easily be tracked within the school building, similarly the movements of customer carrying a store card can easily be tracked within a department store, or within various stores in the same city. There have been concerns on the use of RFID tags, and the debate is mainly focused on the issues related to personal privacy and track-ability.

\subsection{Threat $\rightarrow$ Information overload}

The transfer of information from the BIMs into the 3D urban models if, not controlled with a rule-base or not implemented as query-based transfer/representation can create information overload in 3D urban models. This will mainly be caused by the transfer of, (relatively) redundant semantic information (i.e. information related to the construction stage) and (relatively) redundant detailed geometric information about the some building elements (i.e. the geometry of door/window handles).

\subsection{Threat $\rightarrow$ Unauthorised access to geo-referenced building information}

The implementation will enable every part of the building (and even every building element) to be geo-referenced (i.e. these elements and parts of a building can be referred by real world geo- 
graphic coordinates). The unauthorised access to this type of geo-referenced building information for vulnerable buildings (i.e. buildings in-risk, such as government or military offices) can cause security threats at national level, as the access to this kind of information can aid in terrorist attacks (by enabling accuracy in finding the targets when attacking to a specific room or part of a building).

\section{DISCUSSION AND CONCLUSION}

In recent years there have been academic and industrial efforts for transferring information from the BIMs into the geospatial environment. Some of these efforts (Isikdag, 2006; IfcExplorer, 2008; Safe Software, 2008; OWS-4 Summary Document,2007) have successfully demonstrated that it is possible to transfer information from the BIMs and represent it within the geospatial environment(i.e in form of geospatial models). This paper have presented a SWOT analysis on the implementation of BIMs within the geospatial context for,

- Outlining the advantages and disadvantages that appear as a result of using BIMs in acquiring building information and transferring it into the geospatial environment

- Presenting the opportunities/threats that the implementation might bring to the AEC and urban management domains

A summary of the analysis is given in form of a SWOT matrix, in Table 1.

Table 1: The SWOT Matrix for the implementation of BIMs in geospatial context

\begin{tabular}{|c|c|c|}
\hline \multicolumn{3}{|c|}{ The SWOT Matrix } \\
\hline & Strengths & Weaknesses \\
\hline $\begin{array}{l}\text { Technical } \\
\text { Perspective }\end{array}$ & $\begin{array}{ll}\text { - } & \text { 3D Representation of Building Geometry } \\
\text { - } & \text { Spatial Hierarchy represented within an } \\
\text { Object Oriented Data Model } \\
\text { - } \\
\text { - } \quad \text { EvMs contain Rich Semantic Information } \\
\text { - } \quad \text { Quent State of the Building } \\
\text { ometry } \\
\text { - Clear space subdivision }\end{array}$ & $\begin{array}{l}\text { Differences in geometric represen- } \\
\text { tation of objects in AEC and Geo- } \\
\text { spatial Information Domains } \\
\text { - } \quad \text { BIMs use local and relative coordi- } \\
\text { nates } \\
\text { - Spatial relationships are not stored } \\
\text { in form of connectivity relation- } \\
\text { ships } \\
\text { - Multiple geometrical representa- } \\
\text { tions } \\
\text { - Class differences }\end{array}$ \\
\hline & Opportunities & Threats \\
\hline $\begin{array}{l}\text { Domain } \\
\text { Perspective }\end{array}$ & $\begin{array}{l}\text { AEC domain: } \\
\text { - } \quad \text { Facilitating Site Selection } \\
\text { - } \quad \text { Evaluation of Design Proposals } \\
\text { - } \quad \text { Integrititing the analysis on energy con- } \\
\text { - } \quad \text { large-scale 4D simulations } \\
\text { - } \quad \text { renovessment of damage (and in support } \\
\text { Urban Management domain: } \\
\text { - } \quad \text { Facilitating 3D Modelling of Urban Envi- } \\
\text { - } \quad \text { Fanment } \\
\text { - } \quad \text { 3D geo-coding } \\
\text { - } \quad \text { Registration of Ownership Rights in 3D } \\
\text { - } \quad \text { Padastre } \\
\text { Proplic Participation } \\
\text { Property Tax Evaluation }\end{array}$ & $\begin{array}{ll}- & \text { Limitations on personal privacy } \\
\text { - } & \text { Information overload } \\
\text { - } & \text { Unauthorised access to geo- } \\
& \text { referenced building information }\end{array}$ \\
\hline
\end{tabular}


In technical terms, the main strength of BIMs, is representation of building geometry in 3D and storing rich semantic information. The implementation of evolving model concept within the geospatial environment can facilitate the FM tasks and enables the use of urban models that can provide up-to-date information about the buildings. The difference in geometric representations (caused by different model semantics), the use of local coordinate systems in BIMs and class differences appear as the biggest hurdle in the transformation process.

The main opportunity that this implementation can provide will be in facilitating the 3D indoor modelling. 3D indoor modelling will have direct effect on easing the indoor navigation which will result in facilitating the emergency response and evacuation activities, and delivery of goods and services. The AEC industry can benefit from better automation of site selection process and the integration of logistics operations into the 4D simulations. On the other hand the delivery of goods can be facilitated by seamless integration of indoor and outdoor navigation. The implementation of BIMs in geospatial environment will also assist AEC professionals and urban planners when evaluating a design proposal which will affect (and be affected by) the various elements of urban fabric.

The implementation of BIMs in geospatial environment can not be regarded as (and will not be in form of) a seamless information integration, due to geometric and semantic differences that exist between BIM and GI models. In addition, BIMs will always contain more geometric and semantic information, and more accurate building information when compared with the building models that are residing inside the digital city models. In other words, BIMs will continue to act as information resources for LOD N of a Digital City Model (with N LODs).This metaphor can be denoted as

\section{(GS in) BIM $\geq(G S$ in) Building Model in Digital City Model LOD N}

\section{(where $N \geq 0$ and $G S=$ The level and amount of geometric and semantic information)}

In fact, opportunities offered by the implementation in AEC and Urban Management domains, definitely makes the efforts towards enabling this implementation worthwhile. Although facilitating the evacuation activities and delivery of goods and services can be seen as the biggest gains of such an implementation today, it should be noted that in the future, many location based services and which are related to the indoor navigation and various AEC/Urban Management related tasks will inevitably benefit from such an implementation (or at least from the rich semantic information contained in BIMs).

\section{REFERENCES}

Apirumanekul, C., Mark, O. 2001. Modelling of Urban Flooding in Dhaka City. In Proceedings of 4th DHI Software Conference, Denmark, 2001, http://www.dhisoftware.com/book/materials/book/DHIDhaka_formatted4.pdf [last accessed 02-2005]

Arayici, Y. 2007 An approach for real world data modelling with the 3D terrestrial laser scanner for built environment, Automation in Construction 16 (6): 816-829

Avison, D., Fitzgerald, G. 1996 Information Systems Development, McGraw-Hill, Berkshire, UK

Beal, J.R. 2003 Contextual geo-location, a specialized application for improving indoor location awareness in wireless local area networks, In Proceedings of MICS2003: The 36th Annual Midwest Instruction and Computing Symposium

Brown, E.H., Johnson, B.L. 2005 Using GIS to derive base flood elevations for Building Permits, In Proceedings of ESRI 2005 User Conference, http://gis.esri.com/library/userconf/proc05/papers/ pap1171.pdf [last accessed 06-2006]

Campana, N.A., Tucci, C.E.M. 2001 Predicting floods from urban development scenarios: Case study of the Diluvio Basin,Porto Alegre,Brazil, Urban Water, 3(1): 113-124

CityGML Implementation Specification. 2007. Candidate OpenGIS Implementation Specification (City Geography Markup Language) https://portal.opengeospatial.org/files/?artifact_id=16675 [last accessed 12-2007]

Cote, P. B. 2002. Real Infrastructure for Virtual Cities: Lessons learnt modelling urban environments at the Harvard Design School, In Proceedings of ESRI 2002 User Conference, http://gis.esri.com/library/userconf/proc02/pap1325/p1325.htm [last accessed 10-2004]

Divercity Handbook 2003, The Handbook for EU Research Project Divercity, University of Salford 
Gallaher, M. P., O’Connor, A.C., Dettbarn Jr., J.L., Gilday, L.T. 2004. Cost Analysis of Inadequate Interoperability in the U.S. Capital Facilities Industry, NIST Publication GCR 04-867, Available online at: http://www.bfrl.nist.gov/oae/publications/gcrs/04867.pdf [last accessed 04-2006]

Gunes, A.E., Kovel, J.P. (2000) "Using GIS in Emergency Management Operations" ASCE Journal of Urban Planning and Development, 126(3):136-149

Hello Wall, 2008. IFC Tutorial, http://www.iai-tech.org/services/get-started/hello-world/example-1[last accessed 09-2008]

Howell, I., Batcheler, B. (2005) Building Information Modeling Two Years Later -Huge Potential, Some Success and Several Limitations, http://www.laiserin.com/features/bim/ newforma_bim.pdf [last accessed 02-2006]

IFC Explorer, 2008, Tool for viewing and conversion of IFC models http://www.iai.fzk.de/wwwextern/index.php?id=1040\&L=1[last accessed 06-2008]

Isikdag U., Zlatanova, S. 2008. Towards defining a framework for automatic generation of buildings in CityGML using Building Information Models, Submitted to 3D Geoinfo 08.

Isikdag, U. 2006. Towards the Implementation of Building Information Models in Geospatial Context, $\mathrm{PhD}$ Thesis, University of Salford, UK.

Isikdag, U. Underwood,J., Aouad,G. 2008 An investigation into the applicability of building information models in geospatial environment in support of site selection and fire response management processes. Advanced Engineering Informatics 22(4):504-519

Isıkdag, U., Aouad, G., Underwood, J., Wu, S. 2007. Building Information Models: A review on storage and exchange mechanisms, In Daniel Rebolj (ed.): Proceedings of CIB W78 2007,Maribor, Slovenia Available online at: http://itc.scix.net/cgi-bin/works/Show?w78_2007_97 [last accessed 05-2008]

ISO PAS 16739, 2008 Industry Foundation Classes Release 2x, http://www.iso.org/iso/iso_catalogue/ catalogue_tc/catalogue_detail.htm?csnumber=38056 [last accessed 08-2008]

Kang, Z., Z. Zhang, J. Zhang \& S. Zlatanova, 2007, Rapidly realizing 3D visualisation for urban street based on multi-source data integration, in: Li, Zlatanova\&Fabbri (Eds.) Geomatics Solutions for Disaster Management, Lecture Notes in Geoinformation and Cartography, Springer-Verlag Berlin, Heidelberg, pp. 149-163

Kibria, M.S. 2008. Functionalities of geo-virtual environments to visualize urban projects, MSc Thesis, TuDelft

Lapierre, A. and P. Cote, 2008, Using Open Web Services for urban data management: a testbed resulting from an OGC initiative offering standard CAD/GIS/BIM services, in Coors, M. Rumor, E. Fendel \& S. Zlatanova (eds.): Urban and Regional Data Management; UDMS Annual 2007, Taylor and Francis, London, pp. 381-393

Lee, J. 2004 3D GIS for geo-coding human activity in microscale urban environments In M.J. Egenhofer, C. Freska and H.J. Miller (eds). Proceedings of Third Internatioal Conference GISScience, pp. 162178

Lee,J., Kim,H-Y. 2006 A geocoding method Implemented for Hierarchical Areal Addressing System in Korea The Journal of GIS Association of Korea 14(4):403-419

Mark, O., Weesakul, S., Apirumanekul, C., Aroonnet, S. B., Djordjevic, S. 2004. Potential and limitations of 1D modelling of urban flooding, Journal of Hydrology, 299(3-4):284-299

Meijers, M., Zlatanova, S., Preifer N. 2005. 3D geoinformation indoors: structuring for evacuation, In: Proceedings of Next generation 3D city models, 21-22 June, Bonn, Germany, p. 6

NBIMS. 2006. National BIM Standard Purpose, US National Institute of Building Sciences Facilities Information Council, BIM Committee, http://www.nibs.org/BIM/NBIMS_Purpose.pdf [last accessed 052008]

Noonan, P., Cisson, D. 2001. Challenges in the creation of digital submittal standards for CAD to GIS data transfer, In Proceedings of ESRI 2001 User Conference, http://gis.esri.com/library /userconf/proc01/professional/papers/pap451/p451.htm[last accessed 11-2004]

Omniclass. 2006. Omniclass Construction Classification System, http://www.omniclass.org [last accessed 02-2007]

OWS-4 Summary Document, 2007. OGC Document 07-037r4:Summary of the OGC Web Services, Phase 4 (OWS-4) Available online at: http://www.opengeospatial.org/ projects/initiatives/ows-4 [last accessed 11-2007]

Paul,N., Borrmann,A 2008. Using geometrical and topological modelling approaches in building information modelling, In Alain Zarli and Raimar Schrer (eds) Proceedings of ECPPM 2008, CRC Press, pp.117-127

Pu, S. 2007. Automatic Building modelling from terrestrial laser scanning, In P.Van Oosterom, S. Zlatanova, F.Penninga, E. Fendel (eds). Advances in 3D Geoinformation Systems, LNG\&C,Springer, pp.147-160.

Safe Software, 2008, FME Desktop Translator/Converter Software http://www.safe.com/products /desktop/formats.php [last accessed 06-2008] 
Stoter, J.E. 2004. 3D Cadastre, PhD Thesis, TUDelft

Synchro. 2008. Synchro 4D Project Management, http://www.synchroltd.com[last accessed 09-2008]

Tao, V., 2006. 3D Data Acquisition and object reconstruction for AEC/CAD, in Zlatanova \& Prosperi ( eds.) Large-scale 3D data integration- Challenges and Opportunities, Taylor \& Francis Group, CRCpress, Boca Raton, pp.39-56

Van Oosterom, P., Stotter, J., Janssen, E. 2006. Bridging the worlds of CAD and GIS, In: Zlatanova\& Prosperi (eds.) : Large-scale 3D data integration -Challenges and Opportunities, Taylor\&Francis, Boca Raton, pp.9-36

Vico, 2008. 5D Virtual Contruction Vico Software, http://www.vicosoftware.com[last accessed 09-2008]

Zach, M.H., 1999 Developing a knowledge strategy, California Management Review 41(3): 125-145

Zlatanova, S., S. Pu and W.F. Bronsvoort, 2006, Freeform curves and surfaces in DBMS- a step forward in spatial data integration, In Nayak, Pathan\&Garg (Eds.): Proceedings of the ISPRS Commission IV Symposium on 'Geospatial Databases for Sustainable Development, 27-30 September, 2006, Goa, India; Archives of ISPRS Vol. 36, Part 4A, pp. 407-412 